\title{
DERECHO DE OPCIÓN DEL CONTRATANTE VENCIDO EN JUICIO POR LESIÓN ENORME. ORÍGENES E INTERPRETACIÓN DEL ARTÍCULO 1890 DEL CÓDIGO CIVIL
}

\author{
OPTIONAL RIGHTS OF THE CONTRACTOR DEFEATED IN TRIAL \\ BY LAESIO ENORMIS. ORIGINS AND INTERPRETATION OF THE \\ ARTICLE 1890 OF THE CHILEAN CIVIL CODE
}

\section{Nathalie Walker Silva*}

RESUMEN: La noción de lesión enorme plasmada en el artículo 1890 del Código Civil Chileno se remonta al Derecho romano. Difiere de la lesión enorme del Code Napoléon al poder aplicarse tanto al comprador como al vendedor, y al ser regulada de manera objetiva. El reconocimiento de la lesión enorme por sentencia ejecutoriada abre al contratante un derecho de opción a mantener vigente el contrato, o a consentir en su rescisión, la cual se configura como un tipo especial de nulidad. En caso de rescisión, la parte que ha lesionado siempre se queda con una décima parte del justo precio. Este no es sino uno de los problemas planteados por los efectos del ejercicio de este derecho de opción, siendo el otro la evidente desigualdad entre la suerte del vendedor y del comprador, en desmedro de este último.

Palabras clave: lesión enorme, justo precio, efectos de la rescisión por lesión enorme, recepción de la lesión enorme en el Código Civil chileno.

ABSTRACT: The concept known as laesio enormis which is to be found in article 1890 of the Chilean civil code harks back to Roman law. It is different from the one from the Napoleon Code insofar as it applies to both buyer and seller, according to an objective standard. Once the laesio enormis is acknowledged by the judge, the contract can either remains valid or become null and void, albeit in a distinctive way. If this so-called rescission is called for, the party which was unfair to the other one always keeps a ten percent of the just price. This is the first problem of the consequences of the rescission, the second one being the obvious unbalance between the fates of seller and buyer, to the advantage of the seller.

Key words: laesio enormis, just price, consequences of rescission because of laesio enormis, transposition of laesio enormis in the Chilean civil code.

\footnotetext{
*Profesora de Derecho Procesal, Pontificia Universidad Católica de Chile. Email: nwalker@uc.cl. Licenciada en Ciencias Jurídicas y Doctoranda en Derecho, Pontificia Universidad Católica de Chile. Becaria Conicyt.

La autora le agradece a Marie-Laure Martínez y Carolina Ojeda Muñoz, sus comentarios a este trabajo.
} 


\section{LA LESIÓN ENORME EN EL CONTRATO DE COMPRAVENTA. ORÍGENES DEL CONCEPTO Y SU RECEPCIÓN EN EL CÓDIGO CIVIL}

La lesión enorme es una institución que ha causado arduas controversias en doctrina, en cuanto a sus orígenes, justificación y utilidad ${ }^{1}$.

Se indica con frecuencia que el origen remoto de la lesión enorme está en Roma, con las Leyes 2 y 8 de rescindenda venditionis ${ }^{2}$. Este origen no ha estado exento de discusión en cuanto a la existencia y aplicación de esos rescriptos, atribuidos a los emperadores Diocleciano y Maximiano ${ }^{3}$.

\footnotetext{
${ }^{1}$ Dentro de las posturas más radicales, que le niegan utilidad, encontramos la de Alessandri, quien ha señalado -entre otras razones- que la ley no debe tomar partido por uno de los contratantes cuando existe igualdad de condiciones y capacidad de las partes. Ver Alessandri (1918) p. 1049. En el mismo sentido opina Humberto Silva [Véase Silva (1912) p. 3] y García Goyena (1852) p. 178 y 179.

${ }^{2}$ C. 4 . 44, Lex 2 de rescindenda venditionis: "Impp. Diocletianus et Maximianus A.A. Aurelio Lupo: Rem majoris pretii si tu vel pater tuus minoris distraxerit, humanum est ut, vel pretium te restituente emptoribus, fundum venundatum recipias, auctoritate judicis intercedente, vel si emptor elegerit quod deest iusto pretio recipias: minus autem pretium esse videtur, si nec dimidia pars veri pretii soluta sit".
}

De ambas leyes, esta es la más afamada y citada por la doctrina. Su traducción es la siguiente: "Si tú o tu padre hubiereis vendido a un precio menor una cosa de mayor precio, es razonable o, que restituyendo tú el precio a los compradores, recobres el fundo mediante la autoridad del juez, o bien, si el comprador lo prefiere, recibas tú lo que falta para el precio justo. Parece ser precio menor, si no se ha pagado ni la mitad del precio verdadero". Traducción de García (1962) p. 12.

C. 4, 44, Lex 8: "Si voluntate tua fundum tuum filius tuus venumdedit, dolus et calliditate atque insidiis emptoris argui debet vel metus mortis vel cruciatus corporis imminens detegui, ne habeatur rata venditio. Hoc enim solum, quod paulo minori pretio fundum venditum significans, ad rescindendam venditionem invalidum est. Quod si videlicet contractus emtionis atque venditionis cogitasses substantiam et quod emptor viliore comparandi, venditor cariori distrahendi votum gerentes ad hunc contractum accedant, vixque post multas contentiones, paulatim venditore de eo quod petierat detrahente, emptore autem huic, quod obtulerat, addente, ad certum consentiant pretium, profecto perspiceres, neque bonam fidem, quae emptionis atque venditionis conventionem tuetur, pati neque ullam rationem concedere, rescindi propter hoc consensu finitum contractum vel statim, vel post pretii quantitatis disceptationem; nisi minus dimidia iusti pretii, quod fuerat tempore venditionis, datum est, electione iam emptori praestita servanda".

Traducción: "Si tu hijo -con tu consentimiento- ha vendido tu fundo, para obtener su nulidad, deberás justificar el dolo resultante de los artificios y acechanzas del adquirente, o la amenaza de tormentos corporales, y aun de muerte, que empleó para obligarle a otorgar el contrato. Por cuanto el solo motivo de que alegaras que el fundo no se vendió por su justo valor, no bastaría para hacer rescindir la venta. En efecto, si consideras la naturaleza del contrato de venta; si atiendes a que el vendedor trata de comprar al menor precio posible, y que los deseos del vendedor son los de obtener lo que más pueda, y que no llegan a entenderse ni a ajustar su contrato sino después de muchas discusiones, el vendedor disminuyendo poco a poco el primitivo precio, y el comprador por su parte añadiendo algo a lo primeramente ofrecido, y que al fin convienen en un precio, comprenderás, entonces, que ni la buena fe -que es la esencia del contrato de venta-, ni ninguna otra razón permiten que se te conceda por este solo motivo la rescisión de un contrato terminado por consentimiento mutuo. A no ser que se te hubiese dado un precio menor a la mitad del valor del fundo cuando tuvo lugar la venta, debiéndose en tal caso conceder al comprador la elección arriba ofrecida". Traducción libre, en base a la efectuada por MERELLO (1989) p. 117.

El primer rescripto -Lex 2- aparece fechado en el año 285. El segundo, dataría del año 293. En cuanto a las fechas, resulta lógico considerar que uno de los fundamentos de la rescisión contenida en los rescriptos sería el de proteger a los pequeños terratenientes de las consecuencias de la crisis que sacudió al Imperio Romano en el siglo III d. de C. En este sentido, Manuel Abril Campoy adhiere a esta doctrina, pero considera que el fundamento de la rescisión está en un conjunto de condicionantes, no solo en razones económicas y sociales. Véase Abril (2003) p. 21.

${ }^{3}$ Tampoco esta ley ha estado ajena a la discusión sobre posibles interpolaciones. En este punto, podemos citar, 
Pese a lo anterior, se puede afirmar que las fuentes regularmente consultadas por Bello no manifiestan dudas, al menos en torno a su existencia ${ }^{4}$.

Luego de esos rescriptos, no existe mayor claridad sobre la evolución de la normativa aplicada, antes de ser recogida en las Partidas. Entre nosotros, Alessandri opina que la Lex 2 "no tuvo una aplicación muy frecuente y aun llegó a ser abolida por el emperador Teodosio II"5. Pero a pesar de todo, Justiniano la reprodujo en su Código. Afirma el autor que "solo cuando los Papas Alejandro e Inocencio la proclamaron, a fines del siglo XI y a comienzos del XII, como muy conformes con las doctrinas canónicas, esta institución fue aceptada sin discusión por todas las legislaciones de la época. Por eso la encontramos en Francia y en las leyes españolas"6.

La doctrina de la lesión enorme fue recogida en las Siete Partidas del Rey Alfonso X, quedando asentada en la Partida V, Título 5o, Ley $56^{7}$ y en la Partida IV, Título $11^{\circ}$, ley $16^{8}$.

dentro de muchos ejemplos en igual sentido, a John W. Baldwin: "Grammatical difficulties within the passage itself showed unmistakable evidences of interpolation and raised strong doubts as to its origins during the reign of Diocletian. The terminology showed certain inconsistencies". Véase BALdwin (1599) p. 18. Sin apoyar directamente la tesis de la interpolación de los textos, la expone AвRIL (2003), p. 19. Directo, en cambio, es el apoyo de García VALLES, quien es categórico al afirmar -a modo de resumen- que "el rescripto de Diocleciano fue retocado por Justiniano y por los compiladores posteriores a este. No poseemos el texto primitivo". Véase García Valles (1962) p. 19.

${ }^{4}$ Por ejemplo, la cita García Goyena [Véase García Goyena (1852) p. 177]; Juan Sala, la recoge en su Digesto Romano - Español [Véase SaLA (1844) p. 168] y en su Ilustración del Derecho Real de España [Sala (1820) p. 267; y Pothier la contempla en su Traité du contrat de vente, p. 264.

${ }^{5}$ Alessandri (1918) p. 1047.

${ }^{6}$ AlesSANdRi (1918) p. 1047.

${ }^{7}$ Ley 56, Título 5 de la Partida 5a: "Del ome que por medio o por fuerza compre o vende alguna cosa por menos del justo precio".

Por miedo o por fuerça comprando, o vendiendo algun ome alguna cosa, non deue valer; ante decimos, que deue ser desfecha la compra, si fuer prouado, que la fuerça, o el miedo fue tal, que lo ono de fazer maguer le pasasse. E como quier que la vendida fuesse fecha por jura, o por peño, o por fiadura, o por pena, que fuesse y puesta, no deue valer. Ca despues de vendida, o la compra, que es el principal, non vale, non deuen valer la otras cosas que fuesen puestas por razón della. Otrosi decimos, que se puede desfazer la vendida que fue fecha por menos de la meytad del derecho precio, que pudiera valer en la razón que la fizieron. E si el vendedor esto pudiere prouar, puede demandar al comprador, quel cumpla, sobre aquello que auia dado por ella, tanto cuanto la cosa entonce podria valer según derecho. E si esto non quisiese fazer el comprador, deue desamparar la cosa al vendedor, e recibir del el precio que auia dado por ella. E por menos del derecho precio podría ser fecha la vendida, quando de la cosa que vale diez marauedis fue fecha por menos de cinco marauedis. Otrosi dezimos, que si el comprador pudiere prouar, que dio por la cosa mas de la mitad del derecho precio, que pudiera valer en aquella sazon que la compro, que puede demandar se desfaga la compra, o que baxe el precio, tanto quanto es aquella que demas dio. E este seria, como si la cosa que valiesse diez marauedis, que diesse por ella mas de quince. Esto dezimos que puede fazer, e demandar el vendedor o el comprador, non seyendo la cosa que se vendio, perdida, nin muerta, nin mucho empeorada; ca si alguna de estas cosas le acaesciese, non podría despues fazer tal demanda. Otrosi dezimos, que si el comprador o el vendedor jurare, quando fiziere la compra, o la vendida que maguer la cosa valiesse mas, o menos, que nunca pudiesse demandar, que fuesse desatada la vendida; si fuere mayor de catorze años el que vendio, quando la jura fizo, deue ser guardada la jura: e non se puede desatar entonce la compra, nin la vendida, por tal razón. Mas si fuesse menor de catorze años, non valdria la jura, e desatarse y a la compra o la vendida, tambien como si non ouiesse jurado".

${ }^{8}$ La ley en cuestión se refiere a la apreciación de la dote en el matrimonio, distinguiendo entre dote apreciada y no preciada. Su texto es el siguiente: "apreciada puede seer (sic) la dote quando la establescen ó puede ser que la non apreciaron; et apreciada serie como quando dixiese el que la da: do vos tal casa ó tal viña en dote, et aprésciola en ciento maravedis. Et non serie apreciada como si dixiese simplemiente el que la da: do vos tal heredat ó tal casa en dote: et si la dote fuese apreciada, segunt que es sobredicho, et la apreciasen por mas o por menos de lo que valie- 
De las Siete Partidas, pasa al ordenamiento de Alcalá9 y luego a la Novísima Recopilación, sin modificaciones importantes.

El principio sustentado en las Partidas es incorporado con posterioridad en el Code Napoléon, en el de la Luisiana, el Italiano, el Bávaro, el Austriaco y el Prusiano, con rasgos propios en cada caso ${ }^{10}$. De todos estos cuerpos legales, sin duda el más influyente fue el primero, aunque nuestra recepción final de la teoría de la lesión enorme está en gran parte inspirada también en la normativa existente en las Partidas. Prueba de esto es la nota al artículo 2067 del Proyecto de 1853 -que consagra la lesión enorme en la compraventa-, en que se cita directamente a la Ley 56, título 5, Partida $5^{\text {a11 }}$.

El articulado original del Código Civil chileno no ha sufrido modificación alguna en esta materia a lo largo de los años. Sí ha habido cambios introducidos por leyes especiales, como el artículo 170 del Código de Minería ${ }^{12}$, que hace inaplicable la rescisión de la venta por lesión enorme a la compraventa o permuta de una concesión minera, debido a que se

se, si se sentiere por engañado alguno dellos, puede demandar que sea desfecho el engaño, tambien el que da la dote como el que la rescibe. Et esto se entiende que debe ser guardado en la dote tan solamiente, ça en quanto quier que sea fecho el engaño en mas o menos de lo que vale la cosa, siempre debe seer desfecho, mostrando el engaño segunt que es dicho aquel que se tiene por engañado. Mas esto non est en los otros pleitos; ça non est tenudo de desfacer el engaño el que el feciere, fueras en de si montase mas ó menos dotro tanto del prescio derecho que vale la cosa: et esto serie como si alguno vendiese la cosa que valiese veinte maravedis por quarenta et uno, ó la que valiese quarenta maravedis por diez et nueve".

${ }^{9}$ El texto de la Ley 1a, título XVII del Ordenamiento de Alcalá -que es la Ley 2a, tit. 10 Lib. 10º de la Novísima Recopilación- es el siguiente: "Como se puede desfacer la vendida ó la compra, quando el vendedor se dice engannado en el prescio (Este es el título de la Ley). Si el vendedor, ó comprador de la cosa dixiere que fue engannado en mas de la meytat del derecho prescio, asi como si el vendedor dixiere, que lo que valia diez vendio por menos de cinco, ó el comprador dixiere, que lo que valía diez, que dio por ello mas de quince; mandamos que el comprador sea tenudo á cumplir el derecho prescio que valia la cosa, ó de la dejar al vendedor, tornandole el vendedor el prescio, que rescibio, é el vendedor debe tornar al comprador lo que mas rescibio de la meytat del derecho prescio, ó de tomar la cosa que vendió, é tornar el prescio que rescibio. Et eso mesmo queremos, que se guarde en las rentas, é en los cambios, é en los otros contractos semejantes, é que aya logar esta ley en los contractos sobre dichos, aunque sean fechos por almoneda, é del dia que fueren fechos fasta quatro anuos, é non después.

${ }^{10}$ Así lo expone García Goyena, quien no era partidario de sancionar la lesión. Al exponer las particularidades de la recepción en cada uno de esos Códigos, expresa: "tanta perplejidad y contradicción no son la mejor prueba o apología de la justicia y conveniencia de esta especie de rescisión”. Véase García (1852) p. 178 y 179.

${ }^{11}$ En el "Proyecto Inédito", en cambio, la nota al art. 2067 a, hace referencia a la Ley 16, título 11, Partida 4. Ya se ha transcrito el texto de la Ley en la nota No 8. De esa Ley, lo relevante para nuestro estudio se centra en un ejemplo referido a la compraventa, en los términos siguientes: "Et esto se entiende que debe ser guardado en la dote solamiente, ça en quanto quier que sea fecho el engaño en mas o menos de lo que vale la cosa, siempre debe seer desfecho, mostrando el engaño segunt que es dicho aquel que se tiene por engañado. Mas esto non est en los otros pleitos; ça non est tenudo de desfacer el engaño el que el feciere, fueras en de si montase mas ó menos dotro tanto del prescio derecho que vale la cosa: et esto serie como si alguno vendiese la cosa que valiese veinte maravedis por quarenta et uno, ó la que valiese quarenta maravedis por diez et nueve" (la letra en negrita es nuestra).

12 Art. 170 del Código de Minería: "No hay rescisión por causa de lesión enorme en los contratos de compraventa y de permuta de una concesión o de una cuota o de una parte material de ella".

Otro cambio en la legislación es el que atañe a la forma de entender el concepto de "justo precio", según el artículo 85 de la Ley No 16.742, D.O. 8 de febrero de 1968. Dicho artículo dispone que "para los efectos del artículo 1889 del Código Civil, en los contratos de compraventa celebrados en cumplimiento de promesas de sitios que formen parte de un loteo hecho conforme a la Ley General de Construcciones y Urbanización, se entenderá que el justo precio se refiere al tiempo de la celebración del contrato de promesa, cuando dicho precio se haya pagado de acuerdo con las estipulaciones de la promesa". 
trata de un contrato aleatorio, en el cual la suerte hace que el desequilibrio en las prestaciones sea un elemento de la esencia de dicho contrato.

En cambio, en los sucesivos proyectos de Código Civil, Andrés Bello fue perfilando y adecuando la institución hasta dejarla satisfactoria según los cánones que él manejaba. En cualquier caso, en todos los proyectos de Código, la normativa amparaba tanto al vendedor como al comprador. Al resguardar los intereses de ambos contratantes, se desecha en esta parte la influencia del Code Napoléon, que solo otorga acción rescisoria al vendedor ${ }^{13}$, entendiendo que ha sufrido lesión enorme cuando ha sido perjudicado en más de siete duodécimas partes del precio de la finca. Podrá parecernos extraño, desde la óptica actual, que solo el vendedor que ha sufrido injusticia en el precio pueda alegar lesión y no el comprador. Esto tiene una explicación lógica si valoramos que uno de los fundamentos para incorporar la lesión en el Código Civil francés fue el proteger a los vendedores que celebraban compraventas a precios muy bajos, por la necesidad económica imperiosa que sufrieron al momento de pactar las condiciones del contrato ${ }^{14}$.

\section{2. ¿CUÁNDO SUFREN LAS PARTES LESIÓN ENORME EN EL CONTRATO DE COMPRAVENTA?}

El artículo 1888 elimina cualquier duda en torno a la admisibilidad de la institución en estudio en la compraventa, al señalar que "el contrato de compraventa podrá rescindirse por lesión enorme". Al respecto, resultó meritorio el cambio de la palabra rescisión por la de resolución, que había sido utilizada en el encabezado del título 8 del Proyecto de 1842.

El artículo 1889, por su parte, señala:

"El vendedor sufre lesión enorme, cuando el precio que recibe es inferior a la mitad del justo precio de la cosa que vende; y el comprador a su vez sufre lesión enorme, cuando el justo precio de la cosa que compra es inferior a la mitad del precio que paga por ella. (2) El justo precio se refiere al tiempo del contrato".

El Código no define qué debe entenderse por justo precio. Será el juez quien deba determinarlo al conocer de un litigio en que se reclame la lesión enorme. El justo precio es el resultado de la opinión común ${ }^{15}$. Corresponde al valor venal o precio de mercado, es decir, aquel en que se transan comúnmente los inmuebles, considerando las características

\footnotetext{
${ }^{13}$ En opinión de Planiol, los motivos para negar la acción rescisoria al comprador radicarían en que si él ha consentido en pagar un precio tan elevado es porque podía hacerlo y porque, en su concepto, la cosa valía el dinero que dio por ella. Véase Figueroa (1918) p. 29. Pothier, en cambio, sostiene la opinión contraria. Para este autor, los fundamentos de la lesión no solo se encuentran en la Lex 2, C. de resc. vend., sino también en la naturaleza de los contratos conmutativos: si las partes entienden dar y recibir un equivalente y no lo dan o reciben recíprocamente, deberá rescindirse el contrato sin importar quien es el que resulta perjudicado. Véase Pothier (1821) p. 297.

${ }^{14}$ Fundamento que, a su vez, fue extraído de las Leyes 2 y 8 de resc. vend., que solo conceden acción rescisoria al vendedor.

${ }^{15}$ Robles-VÍA (1897) p. 12 y 13.
} 
particulares que influyen en su valor ${ }^{16}$. En cualquier caso, es indudable que el calificativo de "justo", hace referencia a la equidad que debe reinar en los contratos conmutativos. Es de esta opinión Juan Sala, quien admite que "como la equidad dicta que haya igualdad entre el precio y la cosa vendida, y por otra parte la pública utilidad exige que se cumplan y sean valederos los contratos, (...) [si la desigualdad] fuere en más de la mitad del justo precio, puede rescindirse la venta; pero no si es menor" ${ }^{17}$. Un perjuicio moderado no da lugar a la rescisión, ya que se presume que para evitar pleitos y disminuir la incertidumbre, los contratantes "se remiten mutuamente estos pequeños perjuicios, con tal de que no excedan la mitad del justo precio. De aquí la división del justo precio en sumo, medio e ínfimo, de la que usan frecuentemente los teólogos; a fin de que de otro modo no quede lastimada la justicia conmutativa. (...) Partiendo de estos principios, el Derecho Civil (...) no permitió que sirviera otro perjuicio para la rescisión de una venta sino el que excediese la mitad del justo precio; pues sería ya escandaloso que este se tolerara" ${ }^{18}$.

\section{DERECHO DE OPCIÓN PARA EL CONTRATANTE VENCIDO}

Dispone el artículo 1890 del Código Civil lo siguiente:

"El comprador contra quien se pronuncia la rescisión, podrá a su arbitrio consentir en ella, o completar el justo precio con deducción de una décima parte; y el vendedor, en ese mismo caso, podrá a su arbitrio consentir en la rescisión, o restituir el exceso del precio recibido sobre el justo precio aumentado en una décima parte. (2) No se deberán intereses o frutos sino desde la fecha de la demanda, ni podrá pedirse cosa alguna en razón de las expensas que haya ocasionado el contrato".

La disposición citada presenta bastante similitud con el artículo 1681 del Code Napoléon, pero no haríamos justicia a la labor de Andrés Bello si dijéramos que es una mera reiteración de lo contemplado en el Code. En primer lugar, porque nuestro Código concede acción rescisoria también al comprador. Es destacable que Andrés Bello haya extendido la posibilidad de reclamar la lesión enorme al comprador, ya que en la actualidad no solo es admisible como argumento la imperiosa necesidad que lleva a una de las partes a contratar, sino también la ignorancia de las condiciones en que se ha vendido, la que puede afectar a cualquiera de las dos partes del contrato. Luego, porque ha regulado la lesión con carácter objetivo, no siendo necesario indagar en las causas que provocaron

\footnotetext{
${ }^{16}$ Nuestra jurisprudencia ha dicho que "en nuestro derecho no puede concluirse que el justo precio es el valor intrínseco de lo vendido, sino el valor real que la cosa tiene en el momento del contrato, que no es otro que el que regula la oferta y la demanda en relación con la valorización actual del dinero y con el interés por la adquisición de los terceros. Queda excluido el valor de afección, y su posible valor intrínseco no tiene influencia decisiva. Para determinar el justo precio de la compraventa, y decidir si hubo lesión enorme en el contrato que se pretende rescindir, debe entregarse el valor mismo del bien materia de la negociación a la época del contrato". Véase Patricio Eugenio Díaz Broughton y otros con inmobiliaria Plamher S.A (2009).

${ }^{17}$ SALA (1820) p. 268

${ }^{18}$ SALA (1844) p. 168.
} 
el desequilibrio en las prestaciones ${ }^{19}$, sino solo determinar la desigualdad mediante un cálculo matemático ${ }^{20}$.

Nuestro Código se apartó deliberadamente de la tradición anterior -recogida en las partidas, y que pasó, por ejemplo, a las obras de Sala y Pothier-, en cuanto no consideró a la lesión como un vicio del consentimiento ${ }^{21}$. No se alude a la fuerza ni al engaño, sino que basta con probar en el juicio que se ha sobrepasado el límite admisible de desigualdad en las prestaciones. Quizá sea por esa intención de apartarse de las fuentes, que Bello eliminó el artículo 1638 del Proyecto de 1853, norma que consagraba la lesión como vicio en los contratos conmutativos ${ }^{22}$. En esa misma senda, eliminó también el artículo 1629 del mismo Proyecto, que consideraba como vicios del consentimiento al error, la fuerza, el dolo y la lesión.

El artículo 1890 inciso $1^{\circ}$ da un derecho de opción al contratante contra quien se ha pronunciado la rescisión. Ese derecho consiste, en el caso del comprador, de consentir en la rescisión, o de restituir el exceso del precio recibido por sobre el justo precio, aumentado este en una décima parte. Y en el caso del vendedor, de aceptar la rescisión del contrato -dándose los efectos propios de la nulidad de la compraventa-, o restituir el exceso del precio recibido sobre el justo precio, aumentado este último en una décima parte.

El derecho de opción está establecido como una condición potestativa -además de una obligación facultativa ${ }^{23}$ - que depende del solo arbitrio del contratante que ha lesio-

${ }^{19}$ En tal sentido, el art. 1677 del Code Civil solo admite que el juez dé lugar a la lesión cuando los hechos resulten bastante verosímiles y graves como para hacer presumir la lesión. Una disposición similar fue incorporada por Bello en el artículo 381 del Proyecto de 1847. En ella se establece que: "el que alegue lesión enorme, deberá justificar ignorancia del valor de la cosa al tiempo de perfeccionarse el contrato; ni se tendrá por justa ignorancia la que fuere imputable a negligencia aun leve”. Como puede apreciarse, esta norma era más propia de una lesión-vicio, al atender a la voluntad afectada por la ignorancia o error. Al eliminarse esta norma en el "Proyecto inédito", desaparece con ella el último vestigio de la intención primitiva de Andrés Bello de considerar a la lesión como un vicio del consentimiento.

${ }^{20}$ En este aspecto, es necesario atender al límite del precio irrisorio, ya que si el precio pagado o recibido es tan bajo para llegar a ese extremo, simplemente no hay venta, por no darse cumplimiento a un requisito de existencia del contrato.

${ }^{21} \mathrm{Al}$ respecto, nuestra jurisprudencia ha dicho que: "para las concepciones clásicas, en que se inspira nuestro Código, la lesión no es ni puede ser un vicio del consentimiento: es tan solo un vicio del contrato provocado por el desequilibrio en las prestaciones, que debe ser analizado con carácter objetivo y matemático (...). En cada especie, se verifica matemáticamente la equivalencia, y todas las veces que ella desaparezca, el acto será anulado porque hay enriquecimiento injusto para una persona en desmedro de otra. Véase Ana María Watkins Sepúlveda con Juan Watkins Sepúlveda (2004).

22 Refiriéndose a esta norma, Italo Merello indica que: "no se ve en este precepto referencia a ningún tipo de móvil que actúe como acicate de la voluntad de la víctima explotada por la lesión: no hay indicación subjetiva de causas. Basta la pura existencia objetiva de un determinado arco de desequilibrio patrimonial para que actúe como causa rescisoria, sin que se exija en absoluto que la violación a la justicia conmutativa se haya llevado a cabo por candidez, apremio, impericia u otras circunstancias. Igual que en el tratamiento de la lesión en la compraventa (...) solo se destaca una relación de desequilibrio entre el valor de las prestaciones de las partes. Véase Merello (1979) p. 104.

${ }^{23}$ Así opina Baudry-Lacantinerie, quien dice: "Una vez pronunciada la rescisión, el comprador está obligado a restituir el inmueble vendido, pero es libre para evitar esa restitución pagando el suplemento del justo precio con la deducción establecida. En cuanto al vendedor, no puede exigir este suplemento, cuyo pago es una simple facultad para el comprador. La obligación que este tiene, después que se ha pronunciado la rescisión no es una 
nado al otro. No se otorga a la víctima de la lesión. Se trata de un derecho que deberá ser ejercido solo una vez que se establezca, por sentencia ejecutoriada, la existencia de lesión enorme. Antes, solo existirá una probabilidad de lesión, que solo se transforma en certeza con la sentencia firme.

Cabe destacar que en el Proyecto de 1842, el título XXII, artículo 57 inc. $2^{\circ}$ otorgaba la posibilidad al contratante que incurrió en la lesión, de "dar por nula la venta". El cambio a la normativa actual, que se produjo en el Proyecto de 1853, trajo consigo una mayor propiedad en el uso del lenguaje jurídico. Esto, porque el contratante no "da por nula" la venta, sino que solicita la nulidad al juez, siendo este último quien la declara, no el contratante. Así, en una etapa intermedia, en el Proyecto de 1847, art. 380 inc. 2º se mencionaba la frase "pedir la nulidad", claramente más perfecta que la del citado Proyecto de 1842, y todavía más perfecta que la definitiva "consentir en la nulidad".

También en el Proyecto de 1842 se establecía que, de optar la parte vencida por mantener los efectos del contrato, debía enterar el precio (comprador) o restituir (vendedor) previa avaluación de peritos. La idea de la avaluación pericial fue muy probablemente extraída de la normativa del Code Napoléon, que la contempla para acreditar la existencia de lesión enorme ${ }^{24}$. La norma no prosperó, siendo descartada por Bello ya en el Proyecto de 1847. Con todo, debemos destacar que en los litigios en que se ventila la existencia de lesión, resulta prácticamente ineludible recurrir al dictamen de los peritos ${ }^{25}$.

\section{EFECTOS DEL EJERCICIO DE LA OPCIÓN}

\subsection{El CONTRATANTE VENCIDO CONSIENTE EN LA RESCISIÓN}

Como primera prevención -de tipo semántico-, debemos decir que el contratante vencido no "consiente" en la rescisión. La rescisión es nulidad, y como tal ha de importar una sanción legal, que se aplica sin atender a la voluntad de las partes. Si existe la causal de nulidad y se prueban los hechos invocados como fundamento de la acción, el contrato debe ser dejado sin efecto y, con ello, producirse la extinción de las obligaciones en él contenidas. Sin embargo, se entiende el sentido en que Bello utilizó la palabra consentir. Así como el contratante vencido tiene un derecho de opción que contempla mantener vigente el contrato, tiene también la posibilidad de "consentir", o más bien resignarse a que los efectos de la rescisión se produzcan.

obligación alternativa (...) es una obligación facultativa”. Cfr. BAUdRY-LaCANTINerie: De la vente, número 726 , p. 728, citado por Alessandri (1918) p. 1131.

${ }^{24} \mathrm{El}$ art. 1677 del Code, señala que "no podrá admitirse la prueba de la lesión sino por sentencia, y solo en el caso de ser los hechos articulados bastante verosímiles y graves para hacer presumir la lesión”. El artículo siguiente es categórico en cuanto a que "esta prueba no puede hacerse sino por el informe de tres peritos, los cuales estarán obligados a formar entre todos una sola sumaria y dar un solo dictamen a pluralidad de sus votos".

25 Por citar un par de ejemplos: Moisés Vergara con Luis Vergara (2008): “Considerando octavo. Que la doctrina y jurisprudencia de nuestros tribunales reiteradamente han señalado que para determinar en este tipo de juicios el justo [precio] de venta de una propiedad es menester de forma imprescindible que se efectúe un informe pericial de la propiedad en litigio y si aquella probanza no se produjera en el juicio, indefectiblemente procede que el tribunal rechace la acción intentada al respecto"; Patricio Eugenio Díaz Broughton y otros con Inmobiliaria Plamher S.A. (2009). 
Al tratarse de una nulidad, es aplicable el artículo 1687, en cuanto restituye a las partes "al mismo estado en que se hallarian si no hubiese existido el acto o contrato nulo". Deberán, por tanto, aplicarse las reglas generales sobre nulidad, salvo que -por un principio de especialidad- la ley las modifique. Esto último sucede en lo dispuesto por el artículo 1895, que ordena al comprador que deba restituir la cosa, purificarla previamente de los derechos reales constituidos sobre ella. La norma constituye una clara excepción a los efectos generales de la nulidad, puesto que el efecto retroactivo no es tan intenso como para hacer desaparecer ipso iure los demás derechos reales que existen sobre la cosa. Con ello se busca proteger los derechos adquiridos por los terceros, sin sujetarlos a la incertidumbre de la declaración de nulidad de actos celebrados tiempo atrás sobre la cosa.

Como hemos mencionado con anterioridad, el inciso segundo del art. 1890 señala que "no se deberán intereses o frutos sino desde la fecha de la demanda, ni podrá pedirse cosa alguna en razón de las expensas que haya ocasionado el contrato".

En cuanto a los frutos, este artículo considera al contratante vencido como poseedor de buena fe, ya que, hasta entablarse la acción de rescisión, el comprador ignoraba la existencia de una desigualdad intolerable en las prestaciones. No es más que una aplicación del concepto de buena fe consagrado en el artículo 706. Y es, también, una excepción al art. 907 inc. $3^{\circ}$, que exime al poseedor de buena fe de restituir los frutos percibidos antes de la contestación de la demanda. El artículo 1890, en cambio, se basa en la interposición de la demanda, no en su contestación.

Respecto de los intereses, estos solo se deben desde la fecha de la demanda ${ }^{26}$; en consecuencia, desde el tiempo que media entre la celebración del contrato y la demanda, nada se debe por este concepto.

El inciso segundo del artículo 1890 es muy similar a su par del Code Civil. El artículo 1682 inciso $2^{\circ}$ del Code indica que si el comprador prefiere devolver la cosa y recobrar el precio, restituye también los frutos desde el día de la demanda. El inciso $3^{\circ}$, por su parte, ordena que -asimismo- le corra el interés del precio que pagó desde el día de la misma demanda, o desde el día del pago, si no ha percibido frutos.

Tal como sostiene Alessandri, es bastante probable que la fuente remota de Bello en esta materia haya sido Pothier. En efecto, se puede comparar lo dispuesto en nuestro art. 1890 respecto de las expensas del contrato, con la frase de Pothier: "le vendeur qui a vendu de bonne foi n'est tenu qu'à la restitution du prix, et non au remboursement des frais $d u$ contrat, et de tout ce qu'il en a coûté à l'acheteur pour l'acquisition". La parte final del art. 1890, es muy similar, ya que impide pedir "cosa alguna en razón de las expensas que haya ocasionado el contrato".

Hasta este momento, hemos efectuado el análisis del derecho de opción del contratante vencido como si proviniera de una verdadera nulidad. Pero eso es algo perfectamente discutible.

En primer lugar, es extraño que el contratante vencido, luego de haberse declarado por sentencia firme la existencia de la nulidad del contrato, pueda hacer subsistir la compraventa restableciendo la igualdad en las prestaciones. Si ya existe cosa juzgada en ese jui-

${ }^{26} \mathrm{Si}$ nada se ha estipulado, es lógico que se deban los intereses legales, que son los que operan por defecto, según el artículo 2207 del Código Civil y el art. 28 de la Ley 18.010. 
cio, ¿por qué la ley permite una suerte de "resurrección" del contrato, que ya había muerto con la sentencia ${ }^{27}$ ?

Algunos autores se han preguntado si la lesión enorme es un vicio del consentimiento $y$, al contestar esa interrogante -en forma negativa-, han agregado que la acción rescisoria que emana de la lesión es particular y sus efectos no se rigen por las normas del Título XX del Libro IV del Código Civil, sino por reglas especiales que el Código da en cada caso en que sanciona la lesión y, en especial las contenidas en el Párrafo "De la rescisión de la venta por lesión enorme ${ }^{28}$.

Como puede verse, la rescisión en análisis presenta propiedades muy singulares que la diferencian de otras especies de nulidad ${ }^{29}$. Esto nos lleva a preguntarnos si la rescisión por lesión enorme en la compraventa es una verdadera nulidad; o se trata de una "nulidad sui generis", regulada por Bello en términos tan peculiares que no es posible enmarcarla en los cánones clásicos del Código Civil.

\subsection{El Contratante VenCido RESTABleCE la igUALdAd PERDida}

Si el contratante vencido opta por restablecer el justo equilibrio en la contratación, desaparece con ello la causa para alegar la rescisión y los efectos del contrato pueden mantenerse. Esto implica, en primer lugar, que el comprador podrá conservar la cosa comprada y, si es el vendedor quien ha sufrido la lesión, podrá obtener un precio justo por la cosa que vendió.

Siendo el comprador el contratante vencido en el juicio, podrá completar el justo precio con deducción de una décima parte. Al contrario, si resulta vencido el vendedor -por haber sido él quien provocó la desigualdad-, podrá restituir el justo precio aumentado en una décima parte.

\section{EL PROBLEMA DE LA DÉCIMA PARTE}

Lo primero que podríamos preguntarnos es el porqué de la diferencia de un décimo del precio, que conservan las partes y no restituyen a la otra.

\footnotetext{
${ }^{27} \mathrm{Al}$ respecto, Alessandri Besa es de la opinión de que es posible confirmar el acto nulo por lesión enorme. Pero dicha confirmación solo podría producirse antes de que el juez dicte sentencia. Esto porque la definición de confirmación que el mismo autor da es "la renuncia del derecho de alegar la nulidad". Y solo es posible renunciar a ese derecho antes de demandar la rescisión. Véase Alessandri Besa (2008) p. 261, 276 y 277.

${ }^{28}$ Son de esta opinión: Alessandri Besa (2008), p. 76 y Díez (1993), p. 271.

${ }^{29}$ Infante ha resumido las diferencias con la nulidad ordinaria en tres:

1. La nulidad ordinaria retrotrae a las partes al estado anterior al contrato, como si nunca se hubiese celebrado. En la acción para reclamar la lesión enorme, la ley otorga un derecho de opción, que permite hacer desaparecer la lesión, constituyendo una importante excepción a la nulidad general.

2. El art. 1689 establece que la nulidad juridicialmente pronunciada da acción reivindicatoria contra terceros poseedores de la cosa. En cambio, el art. 1893 niega al vendedor la acción para dirigirse contra los terceros a quienes el comprador haya enajenado la cosa.

3. La nulidad ordinaria, una vez declarada, hace caer todos los gravámenes constituidos sobre la cosa a favor de terceros. El artículo 1895, por el contrario, señala que esta rescisión no acarrea la extinción de los gravámenes reales constituidos sobre la cosa, situando al comprador en la necesidad de purificar la cosa de tales gravámenes.

4. Véase Infante (1958) p. 116 y 117.
} 
La diferencia del diez por ciento que las partes pueden conservar para sí, se ha explicado en doctrina porque ese margen consiste en la legitima ganancia que las partes pueden adquirir producto de la venta, ya que se reconoce como natural el que las cosas no se compren con exactitud al precio que realmente valen ${ }^{30}$.

Tal diferencia, fundada en una supuesta legítima ganancia de las partes, resulta improcedente $\mathrm{y}$, como veremos más adelante, problemática.

Es improcedente, porque si se ha pronunciado la rescisión de la venta por sentencia firme, es porque ha habido tal desigualdad en las prestaciones, que la ley da la posibilidad a la parte afectada de retrotraer los efectos del contrato al estado anterior a la venta. $\mathrm{Ha}$ existido una diferencia tan grande entre las prestaciones de ambas partes que se ha tornado intolerable, y por eso la ley la sanciona. Pero luego, la misma ley -viniendo contra su acto propio-, permite, al que ha causado la lesión, conservar una ganancia que es de suyo ilícita. En otras palabras, ese margen de un décimo resulta injusto, porque proviene del perjuicio experimentado por una parte y que solo se hubiese justificado si hubiese provenido de un contrato celebrado en condiciones mínimamente equitativas, y no es el caso.

Por otro lado, es una diferencia problemática, porque es inductiva a error. La frase utilizada por el artículo al referirse a la opción del vendedor es ambigua. Dice el art. 1890 inciso $1^{\circ}$, en la parte referida: "y el vendedor en el mismo caso, podrá a su arbitrio consentir en la rescisión, o restituir el exceso del precio recibido sobre el justo precio aumentado en una décima parte". Esta frase puede ser entendida de dos maneras que nos llevarían a soluciones bien distintas.

Una primera alternativa sería considerar que lo que se aumenta es el justo precio y ese resultado a su vez se resta de lo recibido. Así, si el justo precio es 100 y el comprador ha pagado 210, el justo precio debe ser aumentado en una décima parte (110) y esto se resta a los 210 recibidos por el vendedor. Es decir, este último devuelve 100.

Una segunda alternativa implica interpretar que el aumento de un décimo a que se refiere la norma, se aplica sobre "el exceso del precio recibido sobre el justo precio". Tomando los datos anteriores, si el justo precio es 100 y el exceso del precio recibido sobre el justo precio es 110 (210-100), debemos aumentar esta cifra en un décimo. Con lo que concluimos que el vendedor ya no restituye 100, sino 121 .

Ilustremos un poco mejor el ejemplo dado: si Pedro es el vendedor, ha sufrido lesión enorme porque vendió el predio en 40 millones, en circunstancias de que el justo precio es 100 millones. Como se ha decretado la rescisión, si Juan (comprador) quiere mantener los efectos del contrato, deberá pagar a Pedro 50 millones. Tal cantidad resulta al restarle al justo precio un décimo (quedando 90 millones), menos la cantidad efectivamente pagada (40 millones). Por otro lado, si quien sufre la lesión enorme es ahora Juan, significa que él ha pagado más de 200 millones. Pensemos que pagó 210. Para que Pedro pueda mantener vigente los efectos del contrato, deberá restituir al comprador 100 millones. Dicha cifra

\footnotetext{
30 Así, por ejemplo, Carlos Tolosa se pregunta: “¿Qué fundamento tiene el aumento o la disminución de la décima parte a que alude este artículo, según se trata de restituir al comprador o al vendedor? La única razón que se da y que se conoce es la que se hizo valer en el Consejo de Estado francés: ahi se dijo que esa décima parte representaba el legitimo beneficio del comprador, que seguramente no habría comprado si no hubiera tenido en vista algún beneficio ya que casi nunca se compra una cosa en su valor exacto". Vid. Tolosa (1926) p. 30.
} 
resulta de aplicar en forma correcta lo dispuesto en el artículo 1890 inc. $1^{\circ}$, que impone al vendedor la obligación de "restituir el exceso del precio recibido sobre el justo precio aumentado en una décima parte". Lo que significa que primero hay que establecer a cuánto asciende "el justo precio aumentado en una décima parte"-que son 110 millones-, para luego proceder a restarlos del precio pagado por el comprador (210 millones-110 millones), dando el resultado final de 100 millones.

Hubiese sido menos conflictivo que Bello permitiera restablecer a las partes al estado anterior, sin la posibilidad de conservar de la ganancia de la décima parte. De ser así, si el vendedor hubiese experimentado lesión enorme -al vender a menos de la mitad del justo precio-, el comprador hubiese eliminado la lesión al enterar lo que faltaba para completar el justo precio. Y al revés, si fuese el comprador el lesionado, el vendedor podría evitar los efectos de la rescisión devolviéndole al primero lo recibido en exceso del justo precio.

\section{EL PROBLEMA DE LA DESIGUALDAD DE TRATO HACIA EL VENDEDOR Y COMPRADOR}

La doctrina ha opinado en reiteradas ocasiones que la ley no trata de igual manera al comprador que al vendedor, dándole una ventaja a este último ${ }^{31}$. En gran medida, los que así opinan tienen razón. Esto, porque el empobrecimiento que requiere el vendedor para alegar lesión es mucho menor que el que necesita experimentar el comprador.

Así, si el justo precio es 100 , el vendedor tiene que haber recibido menos de la mitad del justo precio, por ejemplo: 49. En este caso, el empobrecimiento que ha experimentado el vendedor es de 51. En cambio, para que el comprador pueda alegar lesión enorme, debió de haber pagado más del doble del justo precio, por ejemplo: 201. En el mismo ejemplo, el vendedor se vio perjudicado en 49 y el comprador en 101 .

¿De dónde proviene, entonces, esta disposición del Código que trata con mayor benevolencia al vendedor lesionado que al comprador?

Esto tiene una explicación histórica, relacionada directamente con las fuentes que sirvieron a Bello para perfilar la institución. El origen de la interrogante planteada puede resumirse en el conflicto laesio ultra dimidium versus laesio ultra duplum, que Guzmán Brito se ha encargado de desarrollar en Chile ${ }^{32}$.

El conflicto se remonta a los glosadores Azo, por un lado, y Martino y compañía, por otro, que utilizaron formas distintas de calcular la lesión. De este modo, Azo interpretaba la Lex 2 aplicando la misma medida a ambos contratantes, aplicando "la fracción mitad siempre al justo precio de la cosa: el vendedor sufre lesión si recibe un precio inferior a la mitad del justo precio de aquella; y el comprador, si paga un precio mayor al justo precio más su mitad también de aquella" 33 -criterio ultra dimidium-; y Martino, en cambio, aplicaba "la fracción mitad a valores distintos: al justo precio de la cosa en el caso del vendedor (cuando recibe un precio inferior a la mitad del justo precio de ella), y al precio pagado en el caso del comprador

31 Véase, por ejemplo, Henríquez (1904), p. 14.

32 Para examinar con detalle los criterios seguidos por el Código para medir la lesión, ver GuZMán BRITO (2005) p. 207 a 251.

33 Guzmán Brito (2005) p. 214. 
(cuando recibe una cosa inferior a la mitad del precio que paga por ella)"34 -criterio ultra duplum-. Así, para Azo, cuando el justo precio de la cosa es 10 y el comprador paga 16, puede pedir la rescisión, porque fue perjudicado en 6 , cifra que es superior a cinco $(=$ mitad del justo precio). En el mismo ejemplo, para Martino y otros, el comprador no podría pedir la rescisión porque no fue perjudicado en más del doble del justo precio de la cosa recibida. Para este segundo criterio, debiese haber pagado al menos $21^{35}$.

Las opiniones contrapuestas de los glosadores se traspasaron a las Partidas. Así, en la V Partida se sigue la doctrina de Azo y en la IV, la de Martino. Es decir, en un mismo cuerpo legal -fuente directa de Andrés Bello- hay dos formas distintas de medir la lesión para el comprador.

Esa contradicción pasa luego a los Proyectos de Código de Andrés Bello, quien cita -y toma como apoyo- la V Partida hasta el Proyecto de 1853, pero en el "Proyecto Inédito" cambia de fuente, tomando como referencia la IV Partida. Fue este brusco cambio de parecer el que introdujo la contrariedad ya indicada, en tanto dificulta al comprador alegar la lesión, que solo podrá reclamar si lo dado por la cosa supera el doble del justo precio y no solo la mitad.

Frente a las críticas que la doctrina efectuó a la supuesta situación privilegiada en que el artículo 1890 habría puesto al vendedor ${ }^{36}$, el mismo Andrés Bello salió en defensa de la fórmula adoptada por la norma. Para lograr este objetivo, publicó un artículo en el

${ }^{34}$ GuZmán Brito (2005) p. 214.

35 GuZmán Brito (2005) p. 214.

${ }^{36}$ Entre tales críticas se encontraba la de Enrique Cood, quien escribió un estudio sobre la lesión enorme en los contratos conmutativos en el cual, según Miguel Amunátegui, censuraba la disposición contenida en el art. 2067 del Proyecto de 1853. La verdad es que esa referencia está equivocada, pues el cambio de criterio solo se hizo manifiesto en el "Proyecto Inédito". Según plantea Alejandro Guzmán Brito, el título dado al artículo por Cood: "La lesión enorme en los contratos conmutativos" da la pista para entender que la crítica iba dirigida al artículo 1638 del Proyecto de 1853, que trataba, precisamente la lesión en ese tipo de contratos. Véase GuzMÁN (2003) p. 239.

El estudio de Enrique Cood señala de manera directa que "en un mismo contrato se concede a una de las partes la acción rescisoria más fácilmente que a la otra". Incluso da un ejemplo para ilustrarlo: "Yo quiero desprenderme de una cosa (valor diez) por otra que tú me has de dar. O tú me das una cosa cuyo valor yace entre cinco o quince, o me das una cuyo valor es menos de cinco, o bien, más de quince. Según nuestra actual legislación, el primero de estos tres casos no da lugar a rescisión; el segundo y el tercero, sí. ¿Es justa la regla? -sí, porque si yo perjudico o soy perjudicado en más de cinco, concede la acción rescisoria; igualmente, si tú perjudicas o eres perjudicado, concede igual acción: igualdad perfecta. Según el proyecto, el tercer caso no da lugar a rescisión, sino cuando el valor de la cosa que tú me das excede de 20 [la alusión a Martino no puede ser más clara]. ¿Es justa la regla? -No, porque yo tengo acción cuando me perjudicas en cinco, y tú no tienes sino cuando te perjudico en diez: desigualdad evidente". Vid. Amunátegui (1958) p. 4.

Como respuesta al escrito de Cood, Bello exclama: "es increíble el embrollo que en una cuestión tan sencilla ha producido la frase justo precio. ¿Qué es el justo precio en el contrato de venta? -el valor monetario de la cosa vendida, el valor de la cosa expresado en dinero- ¿qué es el precio pagado por el comprador? Otro valor monetario. La lesión resulta necesariamente de la razón en que se hallan entre sí estos dos valores monetarios". Continúa diciendo Bello que "la lesión no se mide por números sino por razones geométricas. El que vende por 94 una cosa que vale 100, sufre en su fortuna el mismo menoscabo que el que vende por 4 una cosa que vale 10: ambos son perjudicados en 6; sin embargo, nadie dirá que esta es una razón para que se dé al primero la acción rescisoria que se concede al segundo. -No, replican, no hay paridad, porque en el segundo caso 6 es más de la mitad del justo precio de la cosa vendida [los dardos de Bello ahora apuntan a Azo], y en el primero no". Véase Amunátegui (1958) p. 6. 
periódico "El Araucano" que explicaba con detenimiento la lógica proporcional y no meramente aritmética de la norma. Así, señala que "la regla del proyecto es igual para ambas partes; compara siempre el valor dado con el valor recibido y establece una misma medida de lesión para todos los casos. Nada más sencillo ni más justo"37.

Más sencillo y más justo -a nuestro parecer-, hubiese sido aplicar el criterio de Azo, contemplado hasta el Proyecto de 1853 y eliminar, además, el factor de corrección representado por la décima parte del justo precio.

\section{BIBLIOGRAFÍA}

Abril Campoy, Juan Manuel (2003): La rescisión del contrato por lesión-Enfoque doctrinal y jurisprudencial- (Valencia, Tirant lo Blanch) $476 \mathrm{pp}$.

Alessandri Rodríguez, Arturo (1918): De la compraventa y de la promesa de venta. Memoria de prueba para optar al grado de Licenciado en la Facultad de Leyes y Ciencias Políticas de la Universidad de Chile (Santiago, Imprenta - Litografía Barcelona), Tomo II, $1402 \mathrm{pp}$.

Alessandri Besa, Arturo (2008): La nulidad y la rescisión en el Derecho Civil chileno (Santiago, Editorial Jurídica de Chile), Tomo II, Tercera Edición Actualizada, 515 pp.

Amunátegui reyes, Miguel Luis (1888): Obras completas de don Andrés Bello, Proyecto de Código Civil, 1853 (Santiago, Impreso por Pedro Ramírez), Vol. XII, 644 pp.

Amunátegui reyes, Miguel Luis (1932): Obras completas de don Andrés Bello, "Proyecto Inédito" (Santiago, Edición hecha bajo los auspicios de la Universidad de Chile, Editorial Nascimento), Tomo Quinto, 630 pp.

Amunátegui reyes, Miguel Luis (1958): Antecedentes legislativos y trabajos preparatorios del Código Civil de Chile recopilados por Enrique Cood (Santiago, Comisión Nacional Organizadora del Centenario del Código Civil) $124 \mathrm{pp}$.

Baldwin, John W. (1959): The medieval theories of the just Price: romanists, canonists, and theologians in the twelfth and thirteenth centuries (Philadelphia, American Philosophical Society), New Series, Volume 49, Part 4, 92 pp.

Contreras I., F. Armando (1897): De la rescisión de la venta por lesión enorme. Memoria de prueba para optar al grado de Licenciado en la Facultad de Leyes y Ciencias Políticas de la Universidad de Chile (Los Ángeles, Imprenta de "El Aliancista") 19 pp.

Figueroa Anguita, Hernán (1918): De la lesión enorme. Memoria de prueba para optar al grado de Licenciado en la Facultad de Leyes y Ciencias Políticas de la Universidad de Chile (Santiago, Imprenta Fénix) 45 pp.

García Goyena, Florencio (1852): Concordancias, motivos y comentarios del Código Civil español (Madrid, Imprenta de la Sociedad Tipográfico- Editorial), Tomo III, 512 pp.

García Valles, Ricardo (1962): Rescisión por laesio ultradimidium (Barcelona, Bosch) $132 \mathrm{pp}$.

\footnotetext{
${ }^{37}$ La respuesta de Bello a la opinión contraria -incluidas algunas fórmulas matemáticas para ilustrar la explicación, que no vino al caso repetir acá-, aparece transcrita tanto en AmUNÁtegui (1958) p. 5-6, como en AmUNÁTEGUi (1888), Vol. XII, p. 12-17.
} 
GuZMán Brito, Alejandro (2005): "Las relaciones entre la compraventa, la permuta y la lesión enorme: del Derecho Romano al "Código Civil” de Chile", en: Estudios dogmáticos de Derecho Civil (Valparaíso, Ediciones Universitarias de Valparaíso, Pontificia Universidad Católica de Valparaíso) pp. 207 a 251.

Henríquez L, Andrés (1904): De la lesión enorme en la compraventa civil. Memoria de prueba para optar al grado de Licenciado en la Facultad de Leyes y Ciencias Políticas de la Universidad de Chile (Santiago, Imprenta Aurora) 18 pp.

Infante Pérez cotapos, Óscar (1958): Estudio crítico de la jurisprudencia del Párrafo 13 del Título 23 del Libro IV de la rescisión de la venta por lesión enorme. Arts. 1888 al 1896. Memoria de prueba para optar al grado de Licenciado en la Facultad de Ciencias Jurídicas y Sociales de la Universidad de Chile (Santiago. Editorial Universitaria) 161 pp.

Merello Arecco, Italo (1979): "Antecedentes históricos sobre algunos aspectos del régimen de la lesión enorme en el proceso de formación del Código Civil chileno”, en Revista de Estudios Histórico-Jurídicos, No4, pp. 89 a 117.

Merello Arecco, Italo (1989): "La lesión enorme en la venta de oficios en Indias", en Revista Chilena de Historia del Derecho, No 15, pp. 117 y ss.

Oportot Gatica, Luis (1916): De la rescisión de la venta por causa de lesión enorme. Memoria de prueba para optar al grado de Licenciado en la Facultad de Leyes y Ciencias Políticas de la Universidad de Chile (Santiago, Imprenta Chile) 30 pp.

Orrego Barros, Carlos (1905): La lesión enorme. Memoria de prueba para optar al grado de Licenciado en la Facultad de Leyes y Ciencias Políticas de la Universidad de Chile (Santiago, Imprenta y encuadernación universitaria de S. A. García Valenzuela) 73 pp.

Pardo Buelvas, Rafael (1966): Introducción a la teoría de la lesión enorme. Tesis de Grado para optar al título de Doctor en Ciencias Jurídicas en la Facultad de Derecho y Ciencias SocioEconómicas de la Pontifica Universidad Javeriana (Bogotá, Editora El Diario) 101 pp.

Pothier, Robert Joseph (1821): Traité du contrat de vente, Oeuvres complètes (Paris, Chez Thomine et Fortic, Libraires) Tomo XIII, 500 pp.

Robles- Vía, Carlos (1897): La lesión enorme en el contrato de compraventa y sus precedentes históricos en la legislación civil. Memoria de prueba para optar al grado de Licenciado en la Facultad de Leyes y Ciencias Políticas de la Universidad de Chile (Santiago, Imprenta de la Gaceta) 19 pp.

SAla, Juan (1820): Ilustración del Derecho Real de España (Madrid. Librería de Martínez), Tomo II, Segunda Edición corregida y adicionada por su autor y arreglada la cita de leyes a la Novísima Recopilación, 348 pp.

SAla, Juan (1844): Digesto Romano-español, compuesto en latín para el uso de los juristas, Traducido al castellano por Pedro López Clarós y Francisco Fábregas del Pilar (Madrid, Imprenta del Colegio Nacional de Sordomudos) Tomo I, $242 \mathrm{pp}$.

Silva, Humberto (1912): Algunas observaciones sobre la rescisión por causa de lesión enorme. Memoria de prueba para optar al grado de Licenciado en la Facultad de Leyes y Ciencias Políticas de la Universidad de Chile (Santiago, Imprenta Universitaria) 23 pp.

Tolosa fontecilla, Carlos (1926): De la rescisión de la venta por lesión enorme. Memoria de prueba para optar al grado de Licenciado en la Facultad de Leyes y Ciencias Políticas de la Universidad de Chile (Santiago, Imprenta Echeverría) 72 pp. 
$312 \square \frac{\text { Revista Chilena de Derecho, vol. } 39 \text { Nº 2, pp. } 297 \text { - } 312 \text { [2012] }}{\text { Walker Silva, Nathalie "Derecho de opción del contratante vencido en juicio por lesión enorme" }}$

\section{JURISPRUDENCIA CITADA}

Moisés Vergara con Luis Vergara (2009): Corte Suprema, 8 de septiembre de 2009, ROL 1890-2008.

Patricio Eugenio Díaz Broughton y otros con Inmobiliaria Plamher S.A (2009): Corte Suprema, 21 de enero de 2009, ROL 3329-2007.

Ana Maria Watkins Sepúlveda con Juan Watkins Sepúlveda (2004): Corte de Apelaciones de Santiago, 24 de junio de 2004, ROL 6920-1999. 